\title{
Who Are Diabetic Foot Patients? A Hospital Based Descriptive Study in the Gaza Governorate
}

\author{
Motasem Said Salah \\ Department of Health Sciences, University College of Applied Sciences, Gaza Strip 00972, Palestine
}

\begin{abstract}
Worldwide, Diabetes Mellitus (DM) is now one of common non-communicable diseases. Diabetic Foot Ulcer (DFU) is one of the most important complications of DM due to its frequency and its high risk of evolution to amputation. This study aimed to investigate the characteristics of diabetic foot (DF) patients and their foot ulcers in the Gaza governorate, in order to establish effective national preventive programs in Palestine. Quantitative hospital based descriptive study was carried out between January and April 2014 including all patients $(N=148)$ attending DFU clinic. Medical archives of included patients were utilized and necessary data was collected using predesigned data collection tool. Findings shows, 97 (65.5\%) of study participants were males with mean age 58.5 years. About $96.6 \%$ of DF had type II diabetes. Eighty percent (80\%) of the patient had DM duration for more than 10 years, $91.5 \%$ of patients were doing follow up to control their DM, about two third of cases had poor DM control, and 79.0\% of the patients had hypertension. All DF patients had a sensory neuropathy, $72.6 \%$ had a severe motor neuropathy and $79.9 \%$ had autonomic neuropathy. About $60.8 \%$ had neuropathic ulcer. The amputation rate was $25.7 \%$, with most of them being in the toes $68.4 \%$. In conclusion, DF is most likely to develop in 5th and 6th decades with a long duration of DM and uncontrolled blood glucose level. Male, hypertensive, and type II DM patients are at high risk. Sensory, motor and autonomic neuropathy of patient with neuropathic ulcer is a major etiologic component of most diabetic foot. Emphasis should be directed toward patient education, changes in lifestyle and application of multidisciplinary approach to decrease the incidence of diabetic foot complications in the Gaza Governorate.
\end{abstract}

Key words: Diabetes mellitus, diabetic foot, ulcer, Gaza governorate.

\section{Introduction}

Diabetic Foot Ulcer (DFU) is one of the most important complications of diabetes mellitus (DM) and leading cause of lower limb amputation. It is adds significant morbidity and mortality to patients and affects negatively on health, quality of life and imposing economic burden on the patient and the society as well; leading to long stay in hospital and the need for rehabilitative and home care services [1]. It is a health problem and a leading cause of disability. Nearly 370 million people in the years 2012 suffer from DM which accounts for $8.3 \%$ of the world's population; of these 296 million live in developing countries. It is estimated that this figure will increase to 552 million in 2030 [2].

DFU is also the main cause of impairment by cause

Corresponding author: Motasem Said Salah, Ph.D., assistant professor, research field: health management. of lower limb amputation. Every 20 seconds a lower limb is lost due to diabetes somewhere in the world [3]. Foot complications occur in both forms of diabetes and are related more to the duration of illness rather than to the age at onset of disease [4]. Diabetic patients have suffered from foot ulceration. Despite progress in the prevention treatment, and achieving the healing of established ulcers, Diabetic Foot Ulcer remains a considerable challenge [5]. The development of foot problems is not an expected consequence of having diabetes, indeed, most foot ulcers are preventable. However, a recent study indicated that foot ulcer recurrence is still an unresolved issue. Although several therapies have been described for preventing foot ulcers, the rates of reulcerations are very high [6].

Palestine with more than 1.7 million inhabitants [7] is undergoing remarkable economic and demographic changes in recent years, resulting in a transition from poverty and nutritional deficiency diseases towards 
lifestyle related diseases. Despite rapid economic boom, a large segment of the Palestinian population still lives in poverty and will increase the anticipated of burden DM in the coming years. According to the Palestinian Ministry of Health, the total number of new diabetic cases was 3,485 (1,793 in $\mathrm{MOH}$ and 1,692 in UNRWA) with incidence rate of 24.2/10,000 population. One of the most serious complications of DM is the development of foot problems, including ulcerations and subsequent amputations. Foot ulcers develop in approximately $15 \%$ of people with diabetes are a predisposing factor in approximately $85 \%$ of lower limb amputations. These figures reflected that DM and the suspected development of foot complications among diabetic patients in GS are worrying and even though the health care services have been developed since the establishment of the Palestinian National Authority.

However, no or weak national data is available on the overall incidence and prevalence of DFU and disabilities resulting from DM. There is neither effective surveillance system nor community-based screening program to detect the potential cases of DFU among Palestinian people. The current system counts mainly on the visits of the diabetic patients to primary health care centers and depends on mortality data to estimate the impacts of this disease. Therefore, such descriptive study aims to investigate the characteristics of diabetic foot patients and their foot ulcers in Gaza governorate, in order to establish effective national preventive programs to decrease the incidence of DFU and amputation rate among the diabetic patients in Palestine. We wish that the findings of such study will contribute in setting priorities and establishing effective national preventive programs to decrease the incidence of DFU and amputation rate among the diabetic clients in Palestine.

\section{Research Methods}

\subsection{Design and Setting}

A hospital based descriptive study was carried out between January and April 2014 in Al-Shifa Medical Complex at Gaza Strip- Palestine. All patients $(n=148)$ attending diabetic foot clinic during study period were included in the study, in order to project as accurate as possible the results particularly the number of the subjects was not relatively large.

\subsection{Data Collection}

Medical archives of the patients were utilized and necessary data was collected using a predesigned data collection tool adopted from the Ministry of health. The data was collected included information on the patient's age and sex, family history of DM, duration of disease and DFU, method of DM control, history of lower-limb amputation, location, types, and side of the foot ulcer, co-morbidities found during admission, laboratory data, duration of hospitalization, and the outcome.

Neuropathy presents in three forms: motor, sensory and autonomic; each of which has significance in relation to foot ulceration. We considered sensory neuropathy in case of distressing sensations from stabbing, burning pain through to tingling, numbness or actual absence of sensation. Motor neuropathy can result in weakness or paralysis of the muscles controlled by the affected nerve. We also defined autonomic neuropathy as presence of callus and skin dryness.

\subsection{Data Management and Statistical Analysis}

The quantitative data were analyzed using Statistical Package for Social Sciences (SPSS) program version 19.0. The analyses of data were reviewing the filled a predesigned data collection tool, coding the questions, data entry, defining and coding the variables, and data cleaning. Frequency tables of all the variables and cross tabulation of the results were done.

\subsection{Ethical and Administrative Considerations}

An administrative approval was obtained from Ministry of Health-Gaza and Al-Shifa Medical 
Complex director to conduct the study at hospitals. The confidentiality of the information was maintained. Honesty was maintained as well during reporting and analysis of the data with respect to confidentiality and respecting of results.

\section{Results}

Medical archives of 148 patients were included. Among them, 97 (65.5\%) were males and 51 (34.5\%) were females with mean age was 58.5 years. Overall male to female ratio was 1.90: 1 . The baseline characteristics of the study subjects are summarized in (Table 1).

The majority of participants 143 indicated that they had Type II DM (96.6\%) and 5 participants (3.4\%) indicated that they had Type I DM. Only $1.5 \%$ of the patients had DM duration of 5 years or less. Mean Hemoglobin A1C (HbA1C) level was 7.78, and mean patients' fasting blood sugar was $226 \mathrm{mg} / \mathrm{dl}$. A total of $37(25.0 \%)$ patients were under treatment with oral hypoglycaemic agents, $48(32.4 \%)$ were receiving insulin, and $51(34.5 \%)$ were receiving both oral hypoglycaemic agents and insulin. Only $14.2 \%$ of the patients had not reported any history of chronic disease, but approximately $79.0 \%$ of the patients had history of HTN complications. The diabetes mellitus history of the study participants are summarized in Table 2 .

Table 2 shows that the age of the study patients were from 18-69 years (mean $49 \pm 17$ years). Most patients $(38.6 \%)$ were in the age group of 45-60 years. The second highest number of patients $(34.1 \%)$ was in the age group of less than 45 years. Among participants, regarding the knowledge and attitudes on diabetes mellitus and diabetic foot, the awareness level is as follows: $35.2 \%$ were not knowledgeable, $33.1 \%$ were poor knowledge and $31.7 \%$ were knowledgeable.

\section{Discussion}

The outcome of this study contributes to development of knowledge about the diabetic foot in the Gaza Governorate. These findings may be helpful in clinical practice to identify and manage individuals prone to development of diabetic foot.

Table 1 Basic demographic characteristics of the patients $(n=148)$.

\begin{tabular}{ll}
\hline Variable & No $(\%)$ \\
\hline Gender & 148 \\
- Male & $97(65.5)$ \\
- Female & $51(34.5)$ \\
Mean age \pm SD (year) & $58.5 \pm 11.9$ \\
Age (range in year) & $28-87$ \\
Smoking \% & \\
- Yes & 14.2 \\
- No & 85.8 \\
\hline
\end{tabular}

Table 2 History of diabetes mellitus among patients $(n=$ 148).

\begin{tabular}{lc}
\hline Variable & No (\%) \\
\hline Type of DM & $5(3.4)$ \\
\hline - Type I & $143(96.6)$ \\
- Type II & $23(1.5)$ \\
\hline Duration of DM (years) & $29(19.6)$ \\
\hline - 0-5 & $35(23.6)$ \\
- 6-10 & $16(10.8)$ \\
- 11-15 & $45(30.4)$ \\
- 16-20 & $52(35.2)$ \\
- Up 20 & $49(33.1)$ \\
Awareness level of DM (knowledge \& attitudes) \\
- Don't know & $47(31.7)$ \\
- Poor (Incorrect ) & $14(9.5)$ \\
Good (Correct) & $48(32.4)$ \\
\hline Follow up & $77(52.0)$ \\
\hline - No & $9(6.1)$ \\
- Governmental & $6(417(79.0)$ \\
- NGO & $46(31.1)$ \\
- Both & $102(68.9)$ \\
\hline Blood Sugar Level & $48(32.4)$ \\
\hline - Controlled & $51(34.5)$ \\
- Uncontrolled & \\
\hline Type of hypoglycaemic Management \\
\hline - Diet & \\
- Oral & \\
- Insulin & \\
- Mixed oral \& insulin & \\
\hline History of chronic disease & \\
\hline HTN & \\
\hline
\end{tabular}


Table 3 DMF characteristics.

\begin{tabular}{ll}
\hline Variable & Total \\
\cline { 2 - 2 } Do $(\%)$ \\
\hline Yes & $38(25.7)$ \\
No & $110(74.3)$ \\
\hline Level of amputation & \\
\hline Big toe & $26(68.4)$ \\
Trans metal & $7(18.4)$ \\
Below knee & $4(10.6)$ \\
Above knee & $1(2.6)$ \\
\hline Management & \\
\hline Follow up & $78(52.7)$ \\
Dressing & $17(11.5)$ \\
Debridement & $15(10.1)$ \\
Amputation & $38(25.7)$ \\
\hline Neuropathy: sensory & \\
\hline Mild & $29(19.6)$ \\
Moderate & $85(57.4)$ \\
Sever & $34(23.0)$ \\
Neuropathy: motor & \\
Nothing & $40(27.4)$ \\
Mild & $61(41.5)$ \\
Moderate & $36(24.0)$ \\
Sever & $11(7.1)$ \\
\hline Autonomic: callus \& dryness & \\
\hline Yes & $38(79.9)$ \\
\hline No & \\
\hline Neurope of ulcer & \\
\hline Nschemic & \\
\hline
\end{tabular}

The study result revealed that the male patients accounted for $65.5 \%$ of our total study population, consistent with international studies which showed that male had significantly higher rate of DF compared with female $[1,8,9]$. In contrast to this, female seem to develop DF most often than men [10]. It is also revealed that the most of the patients developed DF in 5 th and 6th decades of their life, with the mean age being 58.5 years, a finding which is consistent with other studies have found the average age of developing DF to be about 55-60 years $[1,8,9]$.

The majority of patients with type II diabetes (96.6\%) indicated that they had a diabetic foot. The study results agreed with previous studies that type II diabetes, if not controlled and managed well, may lead also to lower limb complications $[11,12]$. In contrast to that, Alex et al. show that Type I DM usually affects people at early stages of life and it is difficult to be treated or controlled compared to Type II diabetes, and as a sequence, possibility of developing foot complications would be higher [13].

Only $1.5 \%$ of the patients had DM duration of 5 years or less while $80 \%$ of the patient had DM duration more than 10 years. This finding is coincident with other studies showed that the DF increase with years of DM duration and can develop as a long term complication of DM [1, 14]. Additionally, similar results concerning the longer duration of diabetes and development of DFUs were revealed by other researchers $[11,12,15,16]$ who reported that the long duration of DM (10-15 years) can lead to developing DFUs.

Ninety one percent (91\%) of our patients were followed up to control of DM either in governmental health center or non-governmental health center. Most of the cases (68.9\%) had poor DM controlled (as indicated by their $\mathrm{HbA} 1 \mathrm{C}$ level > 7\%), these findings suggest that DF is most likely to develop in a diabetic patients with poor control of blood glucose level $[9,14$, 17]. Similar to several studies [17-19], our results indicated two third of the DF patients do not receive any information or instruction regarding DF and had poor knowledge. Unfortunately, several studies have found that primary care physicians infrequently perform foot examinations in diabetic patients during routine office visits [20,21]. A cross sectional study found that $78.4 \%$ of patients had poor information about foot care [22]. Another study showed statistically significant associations between level of education and effective diabetic foot practice [23]. From the above results, it is clear that uncontrolled blood sugar was associated with awareness levels toward DM and raised the need to pay attention to monitor the effectiveness treatment of what they received in primary health center. 
Based on fact more than $79 \%$ of the patients had hypertension disease. A case control study found that $36 \%$ of cases and $41 \%$ of control had hypertension [17]. These results revealed that hypertension is often related to atherosclerosis, which leads to decreased circulation \& peripheral arterial disease and patients with decreased circulation in their legs \& feet may develop ulcerations that can lead to amputations [24].

In Palestine, no or weak national data is available on the overall incidence and prevalence of DF and amputation resulting DF [17]. Since the year 2013, "Diabetic Foot Unit in Gaza Governorate Hospitals" has been established for prevention and early case detection through patient education and multiple therapies (frequent debridement, drainage, washing, and dressing along with antibiotic therapy and daily assessment of the healing process) managed by a team of vascular surgeon, endocrinologist and nurse specialist. This is consistent with many reports about this approach which reduced the rate of amputation in DF $[8,9,25,26]$. This study also revealed that, $74.3 \%$ of patients healed without amputation while the rate of amputation of our DF patients was $25.7 \%$. The global rate is reported about $14 \%-24 \%$ of the patient [27, 28] and $15 \%$ in western countries [29]. The study results agreed with previous studies from different countries, the rate was 27.2\% in a study in Singapore in 2008 [2] and 28.5\% in Sudan in 2005 [30]. In Iran also there are different reports ranging from $40 \%$ in 1995 and $20 \%$ in 1999 [8] to $28.1 \%$ in 2005 [9]. The most prevalent locations of amputation were toe which accounted $68.4 \%$ followed by transmetal $18.4 \%$ and below knee $10.6 \%$ of the DF amputation. Other researchers have reported similar result, Madanchi $\mathrm{N}$ et al. demonstrated that more than $70 \%$ of the cases have big toe amputations which are prone to ischemia, and diabetic neuropathy and traumas is much more than that of the proximal parts $[1,30]$.

Concerning neuropathy, this study shows that all population had a sensory neuropathy. This finding is consistent with other studies revealed that the risk of neuropathy is increased after 10-12 years of type 2 diabetes duration [31]. Studies in the Arab world showed a prevalence of neuropathy ranging between $38 \%-94 \%$ in diabetic foot cases [32-34]. Sensory neuropathy is a major component leading to the development of diabetic foot ulceration and loss of protective sensations such as pain which may predispose the patients to recurrent injuries without feeling its occurrence [35]. Additionally, $72.6 \%$ of the cases had a motor neuropathy. Ahmed A et al. showed that the development of motor neuropathy with lack of foot care awareness and lack of proper foot wear in Arabian patients significantly contributes to the increasing problems of foot complications in diabetic patients [35]. For autonomic neuropathy, the study showed that $79.9 \%$ of the cases had autonomic neuropathy that leads to dry and cracked skin with fissures. Ahmed et al. revealed that the unique character of weather in most of Arab countries (hot, dry) make it very difficult to change the culture beliefs about footwear which lead to autonomic neuropathy [35].

We also found that most of DFU cases were of the neuropathic $60.8 \%$, followed by the ischemic and neuro-ischemic $25.7 \%$ \& $13.5 \%$ respectively. This result matched with other studies showed the most DFU was neuropathic [36]. In contrast to this, $74.1 \%$ of DFU was ischemic ulcer [1]. Based on the etiological ulcer type, failure to consider the differences in DFU etiology may lead to heterogeneity of results [36].

\section{Conclusion}

Diabetic foot is one of the serious and common complications of diabetes, having negative effects on health, quality of life and is associated with major health care costs. This study aimed to investigate the characteristics of diabetic foot ulcers in Gaza governorate. This study gets its importance because there is no study examines the characteristics of Diabetic foot in the GS. This study might enhance national effort to modify and control of those factors 
and help in developing national preventive programs to decrease the incidence of DFU and amputation rate among the diabetic patients in Palestine. Additionally, this study might increase awareness about diabetic foot among the clients in order to decrease morbidity and mortality from this disease. DF is most likely to develop in 5th and 6th decades of their life with a long duration of DM and uncontrolled blood glucose level. Male patients and type II DM are at high risk. Sensory, motor \& autonomic neuropathy and patient with neuropathic ulcer, is a major etiologic component of most diabetic foot. Emphasis should be directed toward patient education, changes in lifestyle and application of multidisciplinary approach to decrease the incidence of diabetic foot complications in Gaza Governorates.

\section{Acknowledgement}

Firstly, I thank Allah for helping me every moment and during the study. We are indebted to the physicians who care for diabetic foot patients, to staff nurses who deal gently and melodic with patients and to all people those have contributed to the completion of this research.

\section{References}

[1] Madanchi, N., Tabatabaei-Malazy, O., Pajouhi, M., Heshmat, R., Larijani, B., and Mohajeri-Tehrani, M. 2013. "Who Are Diabetic Foot Patients? A Descriptive Study on 873 Patients." Journal of Diabetes Metabolic Disorder 12 (1): 36 .

[2] Wild, S., Roglic, G., Green, A., Sicree, R., and King, H. 2004. "Global Prevalence of Diabetes, Estimates for the Year 2000 and Projections for 2030." Diabetes Care 27 (5): 1047-53.

[3] Whiting, D. R., Guariguata, L., Weil, C., and Shaw, J. 2011. "IDF Diabetes Atlas: Global Estimates of the Prevalence of Diabetes for 2011 and 2030.” Diabetes Res. Clin. Pract. 94 (3): 311-21.

[4] Jeffery, T. W. 2005. "Principles of Management: The Diabetic Foot.” The American Journal of Surgery 190 (2): 295-9.

[5] Griffith, G., and Stonebridge, P. 2002. "Diabetic Foot Disease." In Essential Surgical Practice, Higher Surgical Training in General Surgery, 4th ed., edited by Sir, A. C., Robert, J. C. S., and Abdool, R. M. Arnold, London, 28: 785-99.
[6] Lázaro-Martínez, J. L., Aragón-Sánchez, J., Alvaro-Afonso, F. J., García-Morales, E., García-Álvarez, Y., and Molines-Barroso, R. J. 2014. "The Best Way to Reduce Reulcerations: If You Understand Biomechanics of the Diabetic Foot, You Can Do It.” Int. J. Low Extrem. Wounds 13 (4): 294-319.

[7] Almoutaz, A., Al-Sharief, E., and Al-Sharief, A. 2011. "The Diabetic Foot in the Arab World." The Journal of Diabetic Foot Complications 3 (3): 55-61.

[8] Larijani, B., Afshari, M., Darvishzadeh, F., Bastanhagh, M. H., Pajouhi, M., Baradar Jaili, R., and Moadi, M. 2006. "Lower Limb Amputation in Patients with Diabetic Foot Ulcer: A 22 Year Review." MJIRC 8 (23): 21-4.

[9] Shojaiefard, A., Khorgamim Z., and Larijani, B. 2008. "Independent Risk Factors for Amputation in Diabetic Foot." Int. J. Diab. Dev. Ctries. 28 (2): 32-7.

[10] Bose, K. 1978. "Infection in Diabetic Foot." Ann. Acad. Med. Singapore 7 (2): 359-65.

[11] Aboalfotouh, M., Alfaifi, S., and Al-Gannas, A. 2011. "Risk Factors of Diabetic Foot in Central Saudi Arabia." Saudi Medical Journal 32 (7): 708-13.

[12] Dorresteijn, J. A., Kriegsman, D. M., Assendelft, W. J., and Valk, G. D. 2014. "Patient Education for Preventing Diabetic Foot Ulceration." Cochrane Database Syst. Rev. 16 (12): CD001488.

[13] Alex, R., Ratnaraj, B., Winston, B., Devakiruba, N. S., Samuel, C., John, J., Mohan, V. R., Prasad, J. H., and Jacob, K. S. 2010. "Risk Factors for Foot Ulcers in Patients with Diabetes Mellitus. A Short Report from Vellore, South India." Indian J. Community Med. 35 (1): 183-5.

[14] Nathera, A., Siok Beeb, C., Yiong Huakc, C., Chewa, J. L. L., Lina, C. B., Neoa, Sh. C. B., and Sima, E. Y. 2008. "Epidemiology of Diabetic Foot Problems and Predictive Factors for Limb Loss.” J. Diabetes Complications 22 (2): 77-82.

[15] Hajieh, S., Leila, Y., and Seyyed, L. 2013. "Risk Assessment of Patients with Diabetes for Foot Ulcers According to Risk Classification Consensus of International Working Group on Diabetic Foot.” Pak. J. Med. Sci. 29 (3): 730-4.

[16] Oyibo, O., Jude, B., and Tarawneh, I. 2001. "The Effects of Ulcer Size and Site, Patient's Age, Sex and Type and Duration of Diabetes on the Outcome of Diabetic Foot Ulcers." Diabet Med. 18 (2): 133-8.

[17] Obaid, H., and Eljedi, A. 2015. "Risk Factors for the Development of Diabetic Foot Ulcers in Gaza Strip: A Case-Control Study." International Journal of Diabetes Research 4 (1): 1-6.

[18] Sen, H. M., Sen, H., Aşık, M., Ozkan, A., Binnetoglu, E., Erbağ, G., and Karaman, H. I. 2014. "The Importance of Education in Diabetic Foot Care of Patients with Diabetic 
Neuropathy." Exp. Clin. Endocrinol. Diabetes 123 (3): 178-81.

[19] Ali, S., Basit, A., Mumtaz, S., and Sheikh, T. 2001. "Diabetic Foot Ulcer-A Prospective Study." JPMA 51 (2): 78.

[20] Wylie-Rosset, J., Walker, E. A., Shamoon, H., Engel, S., Basch, C., and Zybert, P. 1995. "Assessment of Documented Foot Examinations for Patients with Diabetes in Inner-city Primary Care Clinics.” Arch. Fam. Med. 4 (1): 46-50.

[21] Bailey, T. S., Yu, H. M., and Rayfield, E. J. 1985. "Patterns of Foot Examination in a Diabetes Clinic." Am. J. Med. 78 (3): 371-4.

[22] Desalu, O., Salawu, F., Jimoh, A., and Adekoya, A. 2011. "Diabetic Foot Care: Self-reported Knowledge and Practice among Patient Attending Three Tertiary Hospital in Nigeria." Ghana Medical Journal 45 (2): 60-5.

[23] Abu-Qamar, M. Z. 2014. "Knowledge and Practice of Foot Self-care among Jordanians with Diabetes: An Interview-based Survey Study." J. Wound Care 23 (5): 247-50, 252-4.

[24] American Podiatric Medical Association. 2016. "Foot Health Information." Accessed February 19, 2016. http://www.apma.org/Learn/FootHealth.cfm?ItemNumbe $\mathrm{r}=1524$

[25] Apelquist, J., and Larsson, J. 2000. "What Is the Most Effective Way to Reduce the Incidence of Amputation in the Diabetic Foot?" Diabetes Metab. Res. 16 (Suppl 1): S75-83.

[26] Ramsey, S. D., Newton, K., Blough, D., McCulloch, D. K., Sandhu, N., and Reiber, G. E. 1999. "Incidence, Outcome and Cost of Foot Ulcers in Patients with Diabetes." Diabetes Care 22 (3): 382-7.
[27] Goldner, M. G. 1960. "The Fate of the Second Leg in the Diabetic Amputee." Diabetes 9 (2): 100-3.

[28] Consensus Development Conference on Diabetic Foot Wound Care. 1999. ADA. Diabetes care 22 (8): 1354-60.

[29] Boulton, A. J. M., and Vileikyte, L. 2000. "The Diabetic Foot: The Scope of the Problem." J. Fam. Pract. 49 (Suppl): S3-8.

[30] Widatalla, A. H., Mahadi, S. I., Shawer, M. A., Elsayem, H. A., and Ahmed, M. E. 2009. "Implementation of Diabetic Foot Ulcer Classification System for Research Purposes to Predict Lower Extremity Amputation." Int. J. Diab. Dev. Ctries. 29 (1): 1-5.

[31] Al-Maskari, F., and El-Sadig, M. 2007. "Prevalence of Risk Factors for Diabetic Foot Complications." $B M C$ Family Practice 8 (1): 59.

[32] Abdullah, M., and Alwahabi. A. 2006. "The Diabetic Foot in the Arab World." Saudi. Med. J. 27 (2): 147-53.

[33] Bantomane, A., Mohammedi, F., Ayed, F., Kadi, K., and Azzouz, A. 2000. "Diabetic Foot Lesions, Etiologic and Prognostic Factors.” Diabetes Metab. 26 (2): 113-7.

[34] Nielsen, J. V. 1998. "Peripheral Neuropathy, Hypertension, Foot Ulcers and Amputation among Saudi Arabian Patients with Type 2 Diabetes.” Diabetes Res. Clin. Pract. 41 (1): 63-9.

[35] Ahmed, A., Elsharief, E., and Alsharief, A. 2011. "The Diabetic Foot in the Arab World." The Journal of Diabetic Foot Complications 3 (3): 55-61.

[36] Yotsu, R., Murase, C., Surgawara, M., Suzuki, K., Nakanaga, K., Ishii, N., and Asiedu, K. 2014. "Comparison of Characteristics and Healing Course of Diabetic Foot Ulcers by Etiological Classification: Neuropathic, Ischemic, and Neuro-ischemic Type." $J$. Diabetes Complications 28 (4): 528-35. 